\title{
Estimated Financial Impacts of Inaccurate Obese Patient Data Recorded by the Western Australian Country Health Service
}

\section{Kim McClean (D) \\ Martyn Cross $(\mathbb{D}$ \\ Sue Reed (D)}

School of Medical and Health Sciences, Edith Cowan University, Joondalup, Western Australia, Australia
Correspondence: Kim McClean

Email k.mcclean@ecu.edu.au
Purpose: Pressure on Australia's healthcare system is increasing annually due to corresponding increases in chronic diseases such as obesity and rapidly ageing population growth across Australia, resulting in requirements for increased funding. This study investigates the financial impact to hospitals due to inaccurate obese patient recording and coding.

Background: Australian healthcare organisations receive Activity-Based Funding (ABF) which provides reimbursement of costs relating to the type of patient care delivered and the resources required for the patient treatment. Accurate healthcare data are essential to ensure accuracy of $\mathrm{ABF}$ and appropriate reimbursement of costs incurred by hospitals that manage obese patients. Managing obese patients results in operational funding requirements such as increased staffing and purchasing of equipment such as hoists, bariatric wheelchairs and bariatric beds, and hospitals must ensure that these clinical requirements are documented accurately in order to be reimbursed of these costs by way of ABF.

Methods: This study identifies the financial implications of inaccurate obesity data within the Western Australian Country Health Service (WACHS) and examines factors that may affect obesity data recording accuracy. The study involves 85 cases of identified obesity data recording inaccuracy that were adjusted by entering corrected obesity codes, which then adjusted Diagnosis-related Groups, National Weighted Activity Units and Activity-Based Funding results.

Results: The study demonstrated estimated annual lost funding opportunities of $\$ 2.23$ million due to obesity coding inaccuracy. An annual average of 616 cases of obesity data inaccuracy was calculated with an average lost funding opportunity of $\$ 3625$ per case. Conclusion: Improvements are required in the clinical recording and coding of patient obesity, such as mandatory recording of patient weight and height data and automated BMI calculations within electronic patient records. Enhanced obesity recording and coding accuracy will result in increased funding opportunities and reduced cost burdens that hospitals currently experience when required to fund obesity-related clinical and safety requirements within operational budgets.

Keywords: obesity, obese, patient admission, coding, administrative data, finances

\section{Introduction}

Although the Australian budget for healthcare services in hospitals is extensive at $\$ 23.6$ billion in 2020-21, this budget supports over 1300 public and private hospitals to provide care for the Australian community. ${ }^{1,2}$ Funding to provide hospital services and care to patients must be carefully managed, however hospital funding is affected by increasing presentations of the ill or injured in hospitals. In 
2018-19, Australian hospitals provided 30.9 million days of patient care, an increase from 28.7 million days of patient care provided in 2014-15. ${ }^{2}$ Increasing Australian population growth, particularly Australia's increasing ageing population of Baby Boomers (people born 1946 and 1966) are contributors to increased requirements for health services, as the probability of requiring healthcare services increases with age. ${ }^{3,4}$ This cohort represent $36 \%$ of all public hospital admissions in 2018-19 and according to the Australian Medical Association, when admitted, they remain hospitalised for $33 \%$ longer than all other age cohorts. $^{4,5}$

A second contributing factor to increased hospital admission is increasing chronic diseases in Australia. The Australian Bureau of Statistics' (ABS) National Health Survey 2017-18 reveals that Australian obesity rates have increased dramatically, from $18.7 \%$ in 1995 to $31.3 \%$ in $2017-18 .^{6}$ Alarmingly, the Australian obesity rate is predicted to reach $42 \%$ by the year $2035 .^{7}$ Significant increase in future risks to healthcare organisations and staff is supported by research that has demonstrated a strong correlation between population obesity rates and obese patients requiring hospital admission, ${ }^{8}$ and the increased likelihood of obese patients requiring hospitalisation than non-obese patients. ${ }^{9,10}$ Additionally, obesity contributes to increased risks of developing other chronic conditions, such as heart disease, diabetes, stroke, chronic kidney disease, cancers and mental health conditions, all of which may also require hospital admission. ${ }^{11}$

Pressure on Australia's healthcare system is increasing annually due to corresponding increases in chronic diseases and rapidly ageing population growth across Australia, resulting in requirements for increased funding for resources including workforce, equipment and infrastructure. ${ }^{12}$ Healthcare organisations receive ActivityBased Funding (ABF) which provides reimbursement of costs relating to the type of patient care delivered and the resources required for the patient treatment. ABF was enacted in 2011 as a result of the National Health Reform Agreement with the aim of increasing transparency of how funds are allocated to hospitals and to give hospitals incentives to use funding more efficiently. ${ }^{13} \mathrm{ABF}$ is payment for the number of patients treated and the type of care required and reflects workload and associated costs incurred by the hospital. Patient care and treatment is recorded and coded through a series of calculations that results in allocation of $\mathrm{ABF}$ to the hospital for the patient treatment. It is essential that accurate clinical recording of care and coding occurs in order for hospitals to be allocated $\mathrm{ABF}$ correctly.

Accurate obesity data is also essential to ensure accuracy of $\mathrm{ABF}$ reimbursement of costs to hospitals that manage obese patients. Managing obese patients results in operational funding requirements such as increased staffing and purchasing of equipment such as hoists, bariatric wheelchairs and bariatric beds, and hospitals must ensure these clinical requirements are documented accurately in order to be reimbursed of these costs by way of ABF. Accuracy of clinical coding of obesity has been examined internationally and has revealed discrepancies between the manual patient files and coded data. ${ }^{14,15}$ A study of obesity data accuracy within the Western Australian Country Health Service (WACHS) was conducted between 2017 and 2019 that involved an examination of 590 patient records which also resulted in findings of poor accuracy, comprising of low average sensitivity results $(40 \%)$, and high average false negative results $(60 \%) .{ }^{16}$ Obesity data recording by clinicians was found to be impacted by lack of knowledge on methods to collect height measurements of patients who are mobility impaired, bedridden or unable to stand due to their health conditions. Poor completeness of obesity data was also impacted by time demands and workload of clinicians, breadth of total clinical recording requirements and lack of organisational direction for the need of obesity data. ${ }^{16}$ McClean, Cross and Reed's study ${ }^{16}$ highlighted the need for an in-depth examination of the financial impact of inaccurate obesity data which may influence healthcare organisations to improve methods of recording obesity data, improve obesity data accuracy and receive accurate ABF reimbursements. This research aims to examine the financial impact to hospitals due to inaccurate obese patient coding.

\section{Methods \\ Design and Setting}

This study employed a quantitative analysis of 85 WACHS Patient Admission data records which were determined to contain obesity data inaccuracies in McClean, Cross and Reed's 2019 manual examination of 590 patient files and electronic records. ${ }^{16}$ The 85 obesity data inaccuracies consisted of 38 cases that were not coded as obese despite weight and height measurements being recorded that allowed an obesity calculation to be determined, and 47 
cases that included records of clinical notations detailing obesity however obesity was not recorded.

When patients are admitted into hospitals, their weight, height, BMI score and/or obesity notations are recorded and utilised for many clinical purposes. On discharge, coding staff analyse patient records and may allocate to the electronic clinical record up to 50 diagnosis codes which represents the treatment(s) provided. Coding of obesity occurs when the condition is identified and affects the patient's clinical management during their hospitalisation, such as altering or adjusting planned treatments, commencing additional treatments or investigative procedures and/or necessitating increases in clinical care. Staff allocate diagnosis codes according to the Australian Coding Standards defined by the Australian Consortium for Classification Development (ACCD). ${ }^{17}$ The Australian Coding Standards is a tool that standardises code definitions and ensures consistency of data across all Australian hospitals. Diagnosis codes form part of complex calculations that result in Diagnosis-related Groups (DRGs) and National Weighted Activity Units (NWAUs) that results in ABF reimbursements to hospitals.

WACHS was selected for this study and previous related studies ${ }^{15,16}$ as population obesity rates are demonstrated to be higher in country locations, ${ }^{18}$ and injury risks to healthcare workers and financial implications to hospitals in country locations will be higher than those in metropolitan locations. WACHS is the largest publicly funded country (rural) health system in Australia and provides health services across Western Australia, an area of 2.5 million square kilometres. ${ }^{19}$

\section{Patient Admission Data}

WACHS Health Information Managers provided deidentified patient admission data from three patient administrations systems, namely WebPAS $^{\circledR}$, TOPAS $^{\circledR}$ and HCARE $^{\circledR}$, to the researchers. Inclusion criteria comprised of patients admitted to hospital for five days or greater and were discharged between 1 July 2015 and 30 June 2017, patients over the age of 18 when admitted to hospital, and who had principal or additional diagnosis of "diabetes mellitus", otherwise known as diabetes type two. Diagnoses of diabetes type two was selected as an inclusion criterion as obesity is categorically connected to diabetes type two. ${ }^{20,21}$ It should be noted that the Australian obesity problem is a greater issue than just type two diabetes; however, this study is limited to only patients with type two diabetes.
The data excluded patient boarder care types including patients who utilised health services use such as outpatient treatments or palliative care, due to these forms of care not aligning to the research requirement of hospital admissions. Patients also excluded from the study included those diagnosed with type one Diabetes Mellitus, patients with a family history of diabetes mellitus, patients with pre-existing diabetes mellitus, descriptions of "type one" or "in pregnancy". These health conditions do not have confirmed links with obesity and diabetes in pregnancy is a potentially temporary condition.

\section{Procedure}

Accuracy of obesity coding was examined by initially identifying patients coded as obese within patient records that met the inclusion criteria. The principal and additional diagnosis codes relating to obesity as defined by the Australian Coding Standards Ninth Edition ${ }^{18}$ are:

E66 - Obesity;

E66.0 - Obesity due to excess calories;

E66.1 - Drug induced obesity;

E66.2 - Extreme obesity with alveolar hypoventilation;

E66.8 - Other obesity;

E66.9 - Obesity, unspecified; and

U78.1 - Endocrine, nutritional and metabolic diseases obesity

WACHS health records that fell within the inclusion criteria were extracted by Health Information Managers, including patients identifiers and episode details (admission and discharge dates). Clinical record staff then extracted the physical patient files in preparation for examination. The principal researcher then conducted a manual examination of the patient files to examine the inclusion or absence of obesity recording, and weight, height and BMI recording. To ensure accuracy of research data, prior to the manual file examination the principal researcher was trained in patient file examination techniques. The Ethics Committees of Edith Cowan University and the WA Country Health Service approved the use of the data in this research, including a waiver of consent for access to patient records.

\section{Data Analysis}

In McClean, Cross and Reed's 2019 study, 85 records were determined to contain obesity data inaccuracies. ${ }^{16}$ This 2020 study utilised recorded weight, height, BMI and/or obesity notations in the 85 patient files to determine correct obesity diagnosis codes. The updated patient 
Table I Variations of DRGs, NWAUs and ABF When Accurate Obesity Codes are Applied

\begin{tabular}{|l|c|c|c|c|c|c|c|c|}
\hline Case & $\begin{array}{c}\text { Obesity Code } \\
\text { Applied }\end{array}$ & $\begin{array}{c}\text { Pre } \\
\text { DRG }\end{array}$ & $\begin{array}{c}\text { Post } \\
\text { DRG }\end{array}$ & $\begin{array}{c}\text { Pre } \\
\text { NWAU }\end{array}$ & $\begin{array}{c}\text { Post } \\
\text { NWAU }\end{array}$ & $\begin{array}{c}\text { Pre- Financial } \\
\text { Costs }\end{array}$ & $\begin{array}{c}\text { Post Financial } \\
\text { Costs }\end{array}$ & $\begin{array}{c}\text { ABF } \\
\text { Increase }\end{array}$ \\
\hline I & E66.92 & G70B & G70A & 0.6612 & 1.3019 & $\$ 3,313$ & $\$ 6,525$ & $\$ 3,212$ \\
\hline 2 & E66.9I & J64B & J64A & 0.8232 & 1.4059 & $\$ 4,125$ & $\$ 7,046$ & $\$ 2,921$ \\
\hline 3 & E66.91 & X63A & X63A & 0.5 & 1.3492 & $\$ 2,567$ & $\$ 6,926$ & $\$ 4,359$ \\
\hline 4 & E66.91 & JI2B & J64A & 0.8232 & 1.4059 & $\$ 4,125$ & $\$ 7,046$ & $\$ 2,921$ \\
\hline 5 & E66.93 & J64A & J64A & 0.8232 & 1.4059 & $\$ 4,125$ & $\$ 7,046$ & $\$ 2,921$ \\
\hline 6 & E66.92 & G70B & G70A & 0.6612 & 1.3019 & $\$ 3,313$ & $\$ 6,525$ & $\$ 3,212$ \\
\hline 7 & E66.91 & O0IB & O0IA & 2.2002 & 3.185 & $\$ 11,027$ & $\$ 15,963$ & $\$ 4,936$ \\
\hline 8 & E66.92 & O60C & O60A & 1.1219 & 1.6418 & $\$ 5,622$ & $\$ 8,228$ & $\$ 2,606$ \\
\hline 9 & E66.91 & O0IB & O0IA & 2.2002 & 3.185 & $\$ 11,027$ & $\$ 15,963$ & $\$ 4,936$ \\
\hline 10 & E66.93 & J64B & J64A & 0.8232 & 1.4059 & $\$ 4,125$ & $\$ 7,046$ & $\$ 2,921$ \\
\hline II & E66.91 & O0IB & O0IA & 2.2002 & 3.185 & $\$ 11,027$ & $\$ 15,963$ & $\$ 4,936$ \\
\hline
\end{tabular}

admission data was resubmitted to determine changes to DRGs and NWAUs, which are used to determine the Activity-Based Funding (ABF) allocated for the patient care. Average ABF financial variations were then extrapolated against WACHS obesity discrepancy rates, ABS population obesity data and WACHS annual admission data and projections to determine the funding effect to WACHS due to obesity data inaccuracies. Patient admission data was supplied by a WACHS Health Information Manager and WACHS patient admission projections were supplied by the WA Health Central Modelling Unit.

\section{Results}

This study examined 85 cases of identified obesity data recording inaccuracy, of which 11 cases resulted in DRG, NWAU and financial variations when the cases were adjusted by entering correct obesity codes. Table 1 displays the summary of the results of the changes to DRGs, NWAUs and ABF finances when correct obesity coding is applied these cases.

Frequency of ABF increases due to obesity inaccuracy was determined and is displayed in Figure 1. The average ABF increase due to obesity data inaccuracy was $\$ 3625$ per case.

A financial variation case rate of $1.86 \%$ was calculated by dividing the total amount of financial variations in this study by the total cases examined and was applied to the estimated obese patient admissions data to determine the number of estimated annual obesity coding discrepancies resulting in $\mathrm{ABF}$ increases. Additionally, the average $\mathrm{ABF}$ increase due to obesity data inaccuracy was applied to determine related estimated annual $\mathrm{ABF}$ variations at WACHS. A summary of the statistical analysis conducted is included in Table 2.

The results show corresponding increases in obesity coding discrepancies align with increasing obesity rates and increasing obese patient admissions over the eightyear period analysed. Annual average cases of obesity inaccuracy are calculated to be 616 cases. Estimated $\mathrm{ABF}$ variations due to obesity coding inaccuracy during this timeframe range from $\$ 2,092,929$ to $\$ 2,456,135$, with an average of $\$ 2,231,520$ per financial year.

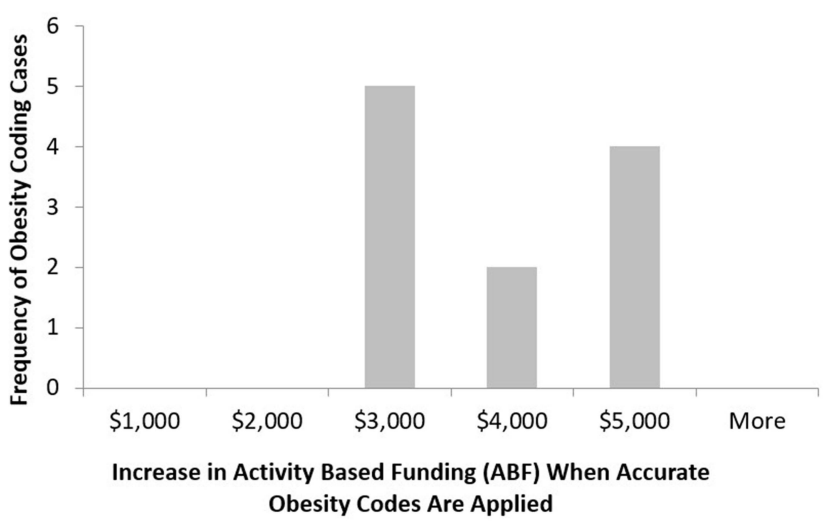

Figure I Frequency Histogram displaying increases in Activity-Based Funding (ABF) when accurate obesity codes are applied. 
Table 2 WACHS Estimated Obese Patient Admissions, Estimated Obesity Coding Discrepancies and Estimated Annual ABF Variation

\begin{tabular}{|l|c|c|c|c|c|}
\hline Financial Year & $\begin{array}{c}\text { Australian } \\
\text { Obesity Rate }\end{array}$ & $\begin{array}{c}\text { WACHS Total } \\
\text { Admissions }\end{array}$ & $\begin{array}{c}\text { Estimated Obese } \\
\text { Patient Admissions }\end{array}$ & $\begin{array}{c}\text { Estimated WACHS Obesity } \\
\text { Coding Discrepancies }\end{array}$ & $\begin{array}{c}\text { Estimated } \\
\text { ABF Variation }\end{array}$ \\
\hline $2013 / 14$ & $29.3 \%$ & 105,708 & 30,972 & 577 & $\$ 2,092,929$ \\
\hline $2014 / 15$ & $29.8 \%$ & 106,074 & 31,610 & 589 & $\$ 2,136,015$ \\
\hline $2015 / 16$ & $30.3 \%$ & 107,978 & 32,717 & 610 & $\$ 2,210,838$ \\
\hline $2016 / 17$ & $30.8 \%$ & 102,391 & 31,536 & 588 & $\$ 2,131,040$ \\
\hline $2017 / 18$ & $31.3 \%$ & 103,902 & 32,521 & 606 & $\$ 2,197,593$ \\
\hline $2018 / 19$ & $31.9 \%$ & 104,956 & 33,470 & 624 & $\$ 2,261,731$ \\
\hline $2019 / 20$ projected & $32.4 \%$ & 108,061 & 35,012 & 653 & $\$ 2,365,882$ \\
\hline $2020 / 21$ projected & $33.1 \%$ & 109,844 & 36,347 & 678 & $\$ 2,456,135$ \\
\hline Annual Average & $31.1 \%$ & 106,114 & 33,023 & 616 & $\$ 2,231,520$ \\
\hline
\end{tabular}

\section{Discussion}

The data analysis of obese patient coding inaccuracy demonstrated substantial financial implications to WACHS funding. The application of ABS obesity rates and the financial variation rate of $1.86 \%$ to WACHS admission data resulted in the finding that an average of 616 annual cases of obesity inaccuracy will occur if obesity data accuracy improvements are not implemented. The number of cases will likely be higher in WACHS regional and remote communities as obesity rates are higher in these areas, ${ }^{18}$ however no ABS obesity data for these communities is available for discrete examination. The cases of obesity data inaccuracy will result in lost $\mathrm{ABF}$ opportunities to WACHS estimated at $\$ 2,231,520$ each financial year. In the current fiscal environment where healthcare funding challenges are frequent, improving obesity clinical recording and coding accuracy to ensure $\mathrm{ABF}$ reflects the clinical impact of caring for obese patients should be a priority. Correcting inaccurate obesity recording results in additional \$3625 ABF per case to hospitals. Additionally, improvements to obese data collection will allow healthcare organisations to enhance obese patient handling safety strategies and reduce risks of injuries to nurses and other healthcare staff, which will also bring about financial benefits such as reduced workers' compensation costs and reduced casual/ agency staff costs incurred to replace injured workers.

Much of the current clinical and safety implications involved in caring for obese patients both at WACHS and generally in Australian hospitals is absorbed within hospital operational budgets. Additional staff are regularly required when managing morbidly obese patients to ensure safe patient handling practices by the staff involved. Lifting or manoeuvring obese patients if mechanical means such as hoists are unavailable, which is common in smaller country hospitals, will often involve two to four healthcare workers and can require even more staff if managing morbidly obese patients. Changes in rehabilitation approaches commonly occur for morbidly obese patients as rehabilitation requirements are extended above the admission health issue to address patient general wellbeing concerns such as mobility.

Obese patients, particularly the morbidly obese, will require utilisation of bariatric equipment or furniture that have higher safe working load ratings such as hoists and slings, bariatric beds, bariatric wheelchairs, bariatric chairs, and bariatric toilets. Both obese patients themselves and this equipment/furniture requires additional hospital space, and therefore bariatric rooms require more hospital space per patient than normal weighted patients. It is common for health services to modify a two person patient room to a one person bariatric patient room. Additional space requirements due to management of obese patients may reduce a hospital's overall room or bed availability and therefore impact a hospital's health servicing ability to its community, which may in time impact on requirements to expand healthcare facilities. Costs for bariatric equipment and building modifications or extensions to accommodate obese patients can be expensive and is often funded out of a hospital's operational budget. Additionally, costs to train staff to safely manage obese patients, particularly the morbidly obese, are often funded by operational budgets rather than ABF. The 
financial impacts to healthcare organisations due to requirements to manage obesity is a hidden cost burden that often requires funding out of operational budgets to ensure both staff and patient safety. Given future projections of Australian obesity rates, financial impacts to healthcare organisations, especially those in county and rural locations, will be significant and planning for future obese patient admissions will be required, including hospital financial models and budget submissions.

Financial implications relating to obese patients also includes increased medications in comparison to normal weighted patients, due to their higher percentage of adipose tissue and lower percentages of water and lean body mass. $^{22}$ Examples of these medications include but are not limited to lipophilic drugs, some chemotherapeutics and some anticoagulants such as Enoxaparin, unfractionated Heparin, Carvedilol, Apixaban, Ribavirin, Prasugrel and Cephazolin, ${ }^{23}$ which can be costly to both patients and the Australian Government by way of the Pharmaceutical Benefits Scheme (PBS) subsidies.

Obesity coding inaccuracies that result in lost funding opportunities are generally attributed to issues relating to recording of patient obesity by clinicians rather than coding practices itself. The recording issues can involve lack of data such as height, weight and/or BMI recording, lack of recording of obesity visually observed by clinicians and lack of recording of changes in patient care due to obesity. It has also been anecdotally reported that obesity recording by clinicians may be impacted by obesity normalisation within society and fear of stigmatising patients. ${ }^{15}$ Further examination is required to develop improvement opportunities that will enhance clinical recording and coding of patient obesity, which will result in reduced ABF variations and increased funding opportunities for hospitals. A manual examination of patient records determined between six to nine locations within the manual patient files for weight, height and/or BMI to be recorded by clinicians. ${ }^{16}$ The multiple recording locations may confuse busy clinical staff and may result in low recording of obesity. As hospitals transition towards electronic health records, future opportunities may be available for mandatory recording of patient weight and height data by clinicians, which could then generate automated BMI calculations within the electronic record. Simplified methods for staff to record changes in clinical care due to the obesity condition should also be considered.

For healthcare organisations maintaining manual patient files, improvements to obesity recording will occur if clinicians are informed on the benefits of accurate obesity data. Education that links the impacts of poor obesity data and potential effects of improved obesity data recording such as enhanced safety of staff who manage obese patients and additional opportunities for funding which could be used for increased resourcing, equipment or training may improve obesity recording. Additionally, strong management direction and policy regarding improved weight, height and BMI recording should be initiated, such as consideration of mandatory recording of obesity data. These improvements will influence a culture shift for improved obesity data recording, ensuring enhanced ability by healthcare organisations to increase safety approaches for staff managing obese patients and recoup finances for obesity-related tasks.

\section{Limitations}

The inclusion criteria of patients only with Type Two Diabetes is a recognised limitation of this study and due to the confirmed links between diabetes and obesity, it is acknowledged that recorded obesity rates in the patient files may differ from obesity rates in the general population. Expansion of the patient inclusion criteria should be considered for future research to allow a broader study of obesity recording accuracy. A second limitation to this study is the clinical accuracy of obesity-related measurements recorded in patient files, which exceeds the scope of this research study. All clinical data within patient files is recorded by trained staff and is considered to be the gold standard for analysis and comparison.

The number and location of rural hospitals in Australia, is though large in number, are spatially remote, and the WA Country Health Service (WACHS) has been selected as a case study. However, WACHS itself incorporates 94 sites country health locations, and time and funding restraints warranted a sample of four sites to be included in the research studies. The four sites were selected as a representation of the vastness of WA country locations and incorporated a variety of population obesity rates in rural and remote locations within Australia. A third limitation of this study was researcher availability to attend rural hospital locations to collect data. While valid results were obtained in this study, future research may require collection of larger data collections and increased researcher availability will require consideration, however future use of electronic health records by hospitals will potentially accommodate remote data collection by researchers, which could reduce this limitation in the future. 


\section{Conclusion}

Australian healthcare services and hospitals are under increasing financial pressure as patient admissions rise annually, due to factors such as increasing population obesity and age-related illnesses. In order to obtain accurate $\mathrm{ABF}$ to fund treatment of obese patient admissions, hospital administrators must ensure accurate clinical recording of obesity. Insufficient obesity data recording currently results in lost $\mathrm{ABF}$ reimbursement which is due to multiple recording locations of height, weight and BMI within patient files, lack of organisational communication regarding requirements for this data and competing clinical workload pressures. Understanding of causes for poor obesity recording should be explored further. Improvement opportunities to increase obesity data recording should be examined such as streamlined data recording locations in both physical and electronic patient files, consideration of mandatory reporting of height and weight, and simplified methods to record changes in patient care due to obesity. Increased accuracy of obesity recording within clinical files of obese patients will ensure ABF will reflect the obesity conditions managed, and healthcare organisations will be funded appropriately.

\section{Data Sharing Statement}

The data that support the findings of this study are available from the corresponding author, Kim McClean, upon reasonable request.

\section{Ethics Approval and Informed Consent}

This study is approved by the Human Research Ethics Committee of Edith Cowan University (Ethics approval number: 2019-00051-MCCLEAN) and the Human Research Ethics Committee of the WA Country Health Service (Ethics approval number: RGS1359). A waiver of consent under section 2.3.10 of the National Statement National Statement on Ethical Conduct in Human Research (Australia) was approved by the Edith Cowan University Human Research Ethics Committee and the WA Country Health Service Human Research Ethics Committee.

\section{Acknowledgments}

We are grateful for the assistance and information gained from staff of the WA Country Health Service, particularly the Health Information Managers and Coding staff, and Ms. Meegan Kidd, Project Officer Clinical Coding.

\section{Author Contributions}

All authors made a significant contribution to the work reported, whether that is in the conception, study design, execution, acquisition of data, analysis and interpretation, or in all these areas; took part in drafting, revising or critically reviewing the article; gave final approval of the version to be published; have agreed on the journal to which the article has been submitted; and agree to be accountable for all aspects of the work.

\section{Funding}

There is no funding to report.

\section{Disclosure}

The authors declare that they have no competing interests.

\section{References}

1. Hunt G. Media release - Budget 2020-21: record health and aged care investment under Australia's COVID-19 pandemic plan; 2020. Available from: https:/www.health.gov.au/ministers/the-hon-greghunt-mp/media. Accessed May 8, 2021.

2. Australian Institute of Health and Welfare. Australia's hospitals at a glance 2018-19. Cat. no. HSE 247. Canberra: AIHW; 2020. Available from: https:/www.aihw.gov.au/reports/hospitals/austra lias-hospitals-at-a-glance-2018-19/summary. Accessed May 8, 2021.

3. Australian Institute of Health and Welfare. Australia's health 2016. Australia's health series no. 15. Cat. no. AUS 199. Canberra: AIHW; 2016. Available from: https://www.aihw.gov. au/getmedia/0b26353f-94fb-4349-b950-7948ace76960/ah16-6-17health-care-use-older-australians.pdf.aspx. Accessed May 8, 2021.

4. Australian Institute of Health and Welfare. Admitted patient care 2018-19 Chapter 3: who used these services?; 2020. Available from: https://www.aihw.gov.au/reports-data/myhospitals/content/ data-downloads. Accessed May 8, 2021.

5. Australian Medical Association. Under pressure and underfunded; 2020. Available from: https://www.amansw.com.au/under-pressureand-underfunded/. Accessed May 8, 2021.

6. Australian Bureau of Statistics. National health survey: first results, 2017-18. ABS cat. no 4364. 0.55.001; 2019. Available from: https:// www.abs.gov.au/ausstats/abs@.nsf/Lookup/by\%20Subject/4364.0.55. 001 2017-18 Main\%20Features Overweight\%20and\%20obesity 90. Accessed December 20, 2019.

7. Walls HL, Magliano DJ, Stevenson CE, et al. Projected progression of the prevalence of obesity in Australia. Obesity. 2012;20 (4):872-878. doi:10.1038/oby.2010.338

8. Pieracci F, Barie P, Pomp A. Critical care of the bariatric patient. Crit Care Med. 2006;34(6):1796-1804. doi:10.1097/01.CCM.0000 217216.84983.0A

9. Galinsky T, Hudock S, Streit J. Addressing the need for research on bariatric patient handling. Rehabil Nurs. 2010;35(6):242-247. doi:10.1002/j.2048-7940.2010.tb00054.x

10. Australian National Preventative Health Agency. Obesity: prevalence trends in Australia; 2014. Available from: http://sydney.edu.au/medi cine/research/units/boden/ANPHA\%20Obesity\%20Prevalence\% 20Trends.pdf. Accessed March 24, 2017. 
11. Department of Health Western Australia. WA healthy weight action plan 2019-2024. 2019. Available from: https://ww2.health.wa.gov. au/-/media/Files/Corporate/general-documents/Health-Networks/WAHealthy-Weight-Action-Plan/PDF/Healthy-Weight-Action-Plan -2019-2024.pdf. Accessed July 21, 2021.

12. Department of Health Australia. Systemic national challenges in health care; 2013. Available from: https://www1.health.gov.au/inter net/publications/publishing.nsf/Content/NPHC-Strategic-Framework $\sim$ systemic. Accessed May 8, 2021.

13. Solomon S. Health reform and activity-based funding. Med J Aust. 2014;200(10):564. doi:10.5694/mja14.00292

14. Martin B, Chen G, Graham M, Quan H. Coding of obesity in administrative hospital discharge abstract data: accuracy and impact for future research studies. BMC Health Serv Res. 2014;14(70):1-8. doi:10.1186/1472-6963-14-70

15. Quan H, Li B, Saunders D, et al. Assessing validity of ICD-9-CM and ICD-10 administrative data in recording clinical conditions in a unique dually coded database. Health Serv Res. 2008;43 (4):1424-1441. doi:10.1111/j.1475-6773.2007.00822.x

16. McClean K, Cross M, Reed S. An audit of obesity data and concordance with diagnostic coding for patients admitted to Western Australian country health service hospitals. Aust $J$ Adv Nurs. 2020;38(1):45-52. doi:10.37464/2020.381.99
17. Australian Consortium for Classification Development. Australian coding standard 9th edition; 2015. Available from: https://www. accd.net.au.

18. Australian Bureau of Statistics (ABS). Overweight and obesity in adults, Australia, 2004-05 (cat. no. 4719.0). Canberra; 2008. Available from: http://www.abs.gov.au/ausstats/abs@.nsf/mf/4719.0/. Accessed October 8, 2017.

19. Western Australian Country Health Service. About Us: regional health services; n.d. Available from: http://www.wacountry.health. wa.gov.au/index.php?id=455. Accessed July 212020.

20. American Society for Metabolic and Bariatric Surgery. Fact sheet: obesity in America. Available from: https://asmbs.org/app/uploads/ 2014/06/Obesity-in-America-1.pdf. Accessed March 16, 2016.

21. Medical Research Council United Kingdom. Diabetes: facts and stats. Diabetes UK. Available from: https://www.mrc.ac.uk/documents/pdf/ diabetes-uk-facts-and-stats-june-2015. Accessed May 21, 2015.

22. Hahler B. Morbid obesity: a nursing care challenge. Medsurg Nurs. 2002;11(2):85-90.

23. Barras M, Legg A. Drug dosing in obese adults. Aust Prescr. 2017;40 (5):189-193. doi:10.18773/austprescr.2017.053
Journal of Multidisciplinary Healthcare

\section{Publish your work in this journal}

The Journal of Multidisciplinary Healthcare is an international, peerreviewed open-access journal that aims to represent and publish research in healthcare areas delivered by practitioners of different disciplines. This includes studies and reviews conducted by multidisciplinary teams as well as research which evaluates the results or conduct of such teams or healthcare processes in general. The journal

\section{Dovepress}

covers a very wide range of areas and welcomes submissions from practitioners at all levels, from all over the world. The manuscript management system is completely online and includes a very quick and fair peer-review system. Visit http://www.dovepress.com/testimonials. php to read real quotes from published authors. 